\title{
Efficient Inhibition of HIV Using CRISPR/Cas13d Nuclease System
}

\author{
Hoang Nguyen ${ }^{1}$, Hannah Wilson ${ }^{1}$, Sahana Jayakumar ${ }^{1}$, Viraj Kulkarni ${ }^{2}{ }^{2}$ and Smita Kulkarni ${ }^{1, *}$ \\ 1 Host-Pathogen Interaction Program, Texas Biomedical Research Institute, San Antonio, TX 78227, USA; \\ hoang.vinhnguyen1990@gmail.com (H.N.); hnwilson2018@gmail.com (H.W.); \\ sjayakumar@txbiomed.org (S.J.) \\ 2 Disease Intervention and Prevention Program, Texas Biomedical Research Institute, San Antonio, TX 78227, \\ USA; vkulkarni@txbiomed.org \\ * Correspondence: skulkarni@txbiomed.org
}

Citation: Nguyen, H.; Wilson, H.; Jayakumar, S.; Kulkarni, V.; Kulkarni, S. Efficient Inhibition of HIV Using CRISPR/Cas13d Nuclease System. Viruses 2021, 13, 1850. https:/ / doi.org/10.3390/v13091850

Academic Editors: Jiri Hejnar and Ben Berkhout

Received: 21 July 2021

Accepted: 10 September 2021

Published: 16 September 2021

Publisher's Note: MDPI stays neutral with regard to jurisdictional claims in published maps and institutional affiliations.

Copyright: (c) 2021 by the authors. Licensee MDPI, Basel, Switzerland. This article is an open access article distributed under the terms and conditions of the Creative Commons Attribution (CC BY) license (https:/ / creativecommons.org/licenses/by/ $4.0 /)$.

\begin{abstract}
Recently discovered Clustered Regularly Interspaced Short Palindromic Repeats (CRISPR)/Cas13 proteins are programmable RNA-guided ribonucleases that target single-stranded RNA (ssRNA). CRISPR/Cas13-mediated RNA targeting has emerged as a powerful tool for detecting and eliminating RNA viruses. Here, we demonstrate the effectiveness of CRISPR/Cas13d to inhibit HIV-1 replication. We designed guide RNAs (gRNAs) targeting highly conserved regions of HIV-1. RfxCas13d (CasRx) in combination with HIV-specific gRNAs efficiently inhibited HIV-1 replication in cell line models. Furthermore, simultaneous targeting of four distinct, non-overlapping sites in the HIV-1 transcript resulted in robust inhibition of HIV-1 replication. We also show the effective HIV-1 inhibition in primary CD4 ${ }^{+}$T-cells and suppression of HIV-1 reactivated from latently infected cells using the CRISPR/Cas13d system. Our study demonstrates the utility of the CRISPR/Cas13d nuclease system to target acute and latent HIV infection and provides an alternative treatment modality against HIV.
\end{abstract}

Keywords: CRISPR/Cas13d; HIV-1; conserved regions

\section{Introduction}

Globally, 37.6 million people are infected with HIV. It is estimated that there are 5000 new infections every day (https://www.hiv.gov/hiv-basics/overview/data-andtrends / global-statistics; accessed on 9 Septempber 2021). The development of combination therapy with multiple highly active antiretroviral drugs (HAART) has led to significantly more diverse treatment options and better quality of life for patients by mitigating against HIV-associated physical deterioration [1]. Efficacious HAART therapy reduces HIV-1 viral load to an undetectable level with a correspondingly high CD4 ${ }^{+}$T-cell count $[2,3]$. HAART therapy is a life-long commitment; disruption in therapeutic adherence can lead to the rapid development of resistant strains, complicating further treatment options and disseminating drug-resistant strains to new hosts [4].

Furthermore, HAART has been shown to cause severe adverse events in many individuals, requiring empiric regimen changes for each, which may further affect adherence and, ultimately, the development of drug-resistant HIV-1 strains [5]. Attempts at HIV eradication have been mostly unsuccessful due to HIV genomic integration and maintenance as a latent reservoir in $\mathrm{CD}^{+} \mathrm{T}$-cells $[6,7]$ and macrophages $[8,9]$. The focus has been diverted towards a functional cure, facilitating viral inhibition without HAART intervention or eradicating the latent reservoir.

RNA interference (RNAi) represents one possible approach to achieve a functional cure for HIV. Small RNAs (si/shRNA) that use cellular RNAi machinery mediate HIV RNA decay efficiently. However, RNA structural constraints, HIV sequence diversity [10-12], viral protein-mediated suppression of cellular RNAi machinery [13-18], and large-scale 
off-target effects [19] are some of the limitations of the RNAi approach. Therefore, we hypothesize that for HIV RNA-targeting strategy to be successful, it must have the following attributes: (1) the mechanism is independent of endogenous RNAi machinery. This significantly reduces the likelihood that the virus can inhibit the mechanism directly; (2) efficient and simultaneous targeting of multiple conserved sites. It has been predicted that the possibility of HIV-1 concurrently mutating at four or more conserved sites is negligible as it entails a great fitness cost to the virus [20-22].

We used the recently discovered Clustered Regularly Interspaced Short Palindromic Repeats, CRISPR/RfxCas13d (CasRx) proteins to meet our above hypothesized criteria. It is a programmable RNA-guided ribonuclease targeting single-stranded RNA (ssRNA) to target HIV-1 transcripts and genome. It has been reported that this ribonuclease is highly efficacious at degrading RNA in mammalian cells, with reduced dependency on RNA structure and significantly lower off-target effects than current siRNA/shRNA technologies [23-26]. We designed guide RNAs (gRNAs) targeting the conserved regions of HIV-1 group-specific antigen (gag), polymerase (pol), and central polypurine tract (cPPT) genes and showed that these gRNAs along with CasRx efficiently inhibit HIV replication. The inhibition of HIV replication was further improved when four distinct sites were targeted simultaneously. Our data show that CasRx protein combined with multiple gRNAs (poly-gRNA) strings simultaneously targeting four different conserved regions in HIV-1 degrades viral RNA efficiently in cell line models and primary cells and suppresses virus reemergence from latently infected cells. Our results suggest a potential utility of CasRx in controlling HIV-1 infection.

\section{Materials and Methods}

\subsection{Plasmids}

The CasRx, (pXR001; Addgene \#109049), dCasRx (PXR002; Addgene \#109050) plasmids, gRNA expression vectors (pXR003, pXR004; Addgene \#109053 and \#109054), Vesicular Stomatitis Virus glycoprotein (VSV-G) envelope expression vector (pMD2.G; Addgene \#12259), lentiviral packaging plasmid (psPax2; Addgene \# 12260), iRFP670 fluorescent reporter vector (piRFP670-N1; Addgene\#79987) and pKLV2-U6gRNA5(BbsI)PGKpuro2ABFP-W (Addgene \#67974) were obtained from the Addgene repository (Watertown, MA, USA).

Construction of pBR43IeG-nef+-iRFP670 HIV vector: The open reading frame (ORF) sequence of iRFP670 amplified from piRFP670-N1 vector by polymerase chain reaction (PCR) using Q $5^{\circledR}$ High-Fidelity DNA Polymerase (New England Biolabs, Ipswich, MA, USA) and primers encoding NcoI and XmaI digestion sites (Supplementary Table S1). The PCR product and pBR43IeG-nef+ (NIH AIDS reporter clone \#11349) were then digested with NcoI and XmaI (New England Biolabs, Ipswich, MA, USA). The digested products were separated by $0.8 \%$ agarose gel electrophoresis and purified using the Monarch ${ }^{\circledR}$ DNA Gel Extraction Kit (New England Biolabs, Ipswich, MA, USA). The purified products were ligated using T4 DNA ligase (New England Biolabs, Ipswich, MA, USA). The ligated product was transformed into Escherichia coli (E. Coli) Stbl competent cells (New England Biolabs, Ipswich, MA, USA). The clones were picked and screened using colony PCR (Supplementary Table S1). The positive colonies were grown in Terrific Broth (Research Products International, Mount Prospect, IL, USA) containing $300 \mu \mathrm{g} / \mathrm{mL}$ ampicillin at $37^{\circ} \mathrm{C}$. The vector sequence was verified by Sanger sequencing (Genewiz, South Plainfield, NJ, USA).

Construction of pKLV2-U6-CasRx-(pre-gRNA)-PGKpuro2ABFP vector: The pKLV2U6-CasRx-(pre-gRNA)-PGKpuro2ABFP vector was constructed using restriction enzyme digestion. The pre-gRNA cassette was PCR amplified using Q $5^{\circledR}$ High-Fidelity DNA polymerase (New England Biolabs, Ipswich, MA, USA) to encode MluI and BamHI digestion sites as described in Supplementary Table S2. One microgram of this PCR product and pKLV-U6gRNA(BbsI)-PGKpuro2ABFP was digested with MluI and BamHI (New England Biolabs, Ipswich, MA, USA). The digested products were purified, ligated, transformed 
into E. coli Stbl competent cells (New England Biolabs, Ipswich, MA, USA), colonies were screened by PCR, positive clones were grown, and the vector sequence was further confirmed by Sanger sequencing as described above. Sanger Sequencing primers are described in Supplementary Table S1.

Construction of pVax-CasRx vector: CasRx-eGFP from pXR001 vector was PCR amplified and cloned into pVax1 (ThermoFisher Scientific, USA) by restriction enzyme cloning. The PCR product was digested with KpnI and XbaI (New England Biolabs, Ipswich, MA, USA) and ligated into pVaxI vector. The expression of CasRx-eGFP was evaluated by transient transfection in HEK293T derived Lenti-X ${ }^{\mathrm{TM}}$ cells (Takara Bio, Mountain View, CA, USA) cells, followed by visualization of eGFP by flow cytometry and confirmation of CasRx expression by qPCR (Primers listed in Supplementary Table S1).

Construction of CasRx-NES vector: Sequence from PXR001 vector was PCR amplified with specific oligonucleotide to exclude NLS sequence and add nuclear export signal of mitogen-activated protein kinase (MAPK). The rest of the backbone sequence of PXR001 was amplified in a separate PCR. Two DNA fragments with overlapping ends were prepared by consecutive PCR reactions with Q5 DNA polymerase. These fragments were then directly transformed into E. coli Stbl (New England Biolabs, Ipswich, MA, USA) for in vivo cloning as previously described [27]. Plasmid DNA extracted from resulting colonies was sequenced to confirm NLS signal removal and NES signal insertion in the CasRx-NES vector.

Single gRNA design and cloning: The single gRNAs were designed to target HIV-1 transcript at highly conserved and siRNA targetable sites using the siVirus software (http: / / sivirus.rnai.jp / HIV / ; accessed on 2 September 2021). These gRNAs were then confirmed for $>70 \%$ genetic conservation with all HIV-1 variants within the Los Alamos National Laboratory HIV database (https://www.hiv.lanl.gov/HIV/; accessed on 2 September 2021). The blast-like alignment tool (BLAT; https://genome.ucsc.edu/cgi-bin/hgBlat; accessed on 2 September 2021) was used to analyze gRNA sequences for potential offtarget binding in the human genes. We confirmed that all gRNAs showed at least three or more mismatches (Supplementary Table S2). Those matching this criterion were cloned into the gRNA expression vector, PXR003 using the golden gate assembly. Primers used for gRNA are listed in Supplementary Table S2. We used the freely available algorithm [28] to predict functional efficacy of gRNAs based on specific sequence and structural features and partition gRNAs into four quartiles (Q1-Q4) with increasing efficacy scores from Q1 to Q4. Next, $10 \mu \mathrm{M}$ of each gRNA primer pair was phosphorylated and annealed in a $10 \mu \mathrm{L}$ reaction containing $1 \mu \mathrm{L}$ of $10 \times$ T4 DNA Ligase Buffer, $0.5 \mu \mathrm{L}$ T4 polynucleotide kinase, and distilled water. Phosphorylation was carried at $37^{\circ} \mathrm{C}$ for $30 \mathrm{~min}$. The primer pairs were annealed by increasing reaction temperature to $95^{\circ} \mathrm{C}$ for $5 \mathrm{~min}$ and allowing the reaction to cool down to $25^{\circ} \mathrm{C}$ at a rate of $5{ }^{\circ} \mathrm{C} /$ minute. The phosphorylated and annealed gRNAs were cloned into PXR003 using a Golden gate cloning reaction. Each reaction contained $1 \mu \mathrm{M}$ annealed crRNA guide oligonucleotides, $25 \mathrm{ng}$ of PXR003, $0.5 \mu \mathrm{L}$ BbsI $(10 \mathrm{U} / \mu \mathrm{L}), 0.5 \mu \mathrm{L}$ T4 DNA Ligase $(400 \mathrm{U} / \mu \mathrm{L}), 1 \mu \mathrm{L}$ of $10 \times$ T4 DNA Ligase Buffer, and distilled water in total $10 \mu \mathrm{L}$. The golden gate amplification was carried out in 30 repeating cycles of $37^{\circ} \mathrm{C}$ for $5 \mathrm{~min}$ and $23^{\circ} \mathrm{C}$ for $5 \mathrm{~min}$. The golden gate mix was transformed into E. coli NEB Stbl competent cells (New England Biolabs, Ipswich, MA, USA) and sequenced with U6 promoter primer listed in Supplementary Table S2.

PolygRNA vectors: Four gRNAs, targeting four distant, non-overlapping sites of HIV-1 genome or non-targeting (NT), along with direct repeat sequences, were collinearly arranged. The entire sequence was commercially synthesized (Genewiz, South Plainfield, NJ, USA) and cloned into pKLV-U6-CasRx-(pre-gRNA)-PGKpuro2ABFP vector using the golden gate assembly with some modifications. The modified $10 \mu \mathrm{L}$ golden gate reaction contained $50 \mathrm{ng}$ of synthesized polygRNA fragment, $25 \mathrm{ng}$ of the pKLV-U6-CasRx-(pregRNA)-PGKpuro2ABFP, $0.5 \mu \mathrm{L}$ BbsI $(10 \mathrm{U} / \mu \mathrm{L}), 0.5 \mu \mathrm{L}$ T4 DNA Ligase $(400 \mathrm{U} / \mu \mathrm{L}), 1 \mu \mathrm{L}$ of $10 \times$ T4 DNA Ligase Buffer, and distilled water. 


\subsection{Cell Culture}

HEK293T derived Lenti-XTM cells (Takara Bio, Mountain View, CA, USA) and TZM-bl cells (ARP-8129; NIH AIDS Reagent Program) [29] were cultured in Dulbecco's Modified Eagle Medium with high glucose, sodium pyruvate, and two mM L-Glutamine (Thermo Fisher Scientific) supplemented with $10 \%$ fetal bovine serum (ThermoFisher Scientific, Waltham, MA, USA) and antibiotic-antimycotic solution (ThermoFisher Scientific, Waltham, MA, USA). Cells were passaged to maintain $<80 \%$ confluence. Jurkat Clone E6-1 (TIB152 ${ }^{\mathrm{TM}}$; ATCC ${ }^{\circledR}$, Manassas, VA, USA) and HIV latency model J1.1 cells (ARP-1340; NIH AIDS Reagents Program) [30] were cultured in RPMI-1640 media supplemented with 2 mM LGlutamine, $10 \%$ bovine calf serum, and $1 \times$ antibiotic-antimycotic (Thermo Fisher Scientific). Primary $\mathrm{CD} 4^{+} \mathrm{T}$ cells were isolated from peripheral blood lymphocytes (commercially available single-donor buffy coats from Innovative research, Novi, MI, USA) and activated with Immunocult ${ }^{\mathrm{TM}}$ human CD3/CD28 T cell activator (Stemcell Technologies, Vancouver, Canada), in the RPMI-1640 media supplemented with $2 \mathrm{mM} \mathrm{L-Glutamine,} 10 \%$ bovine calf serum, and $1 \times$ antibiotic-antimycotic (ThermoFisher Scientific, Waltham, MA, USA) and human recombinant IL-2 (Stemcell Technologies, Vancouver, Canada). Activated CD4+ T cells were transfected with pVax-CasRx and gRNA plasmids by nucleofection using Lonza $4 \mathrm{~d}$ nucleofector. Eighteen hours after nucleofection, the cells were infected with HIV-iRFP virus particles. Virus replication was measured by flow cytometry after $48 \mathrm{~h}$ of infection.

\subsection{Production of Virus}

The pBR43IeG-nef+-iRFP670 vector was transfected either by itself or with VSV-G envelop plasmid (PMD2.G) into Lenti- $\mathrm{X}^{\mathrm{TM}}$ cells using Transit-X2 (Mirus Bio, LLC, Madison, WI, USA) to make XR-4 tropic or VSV-G pseudotyped HIV-iRFP virus, respectively. Antiviral supernatant was harvested 48 and $72 \mathrm{~h}$ following transfection, centrifuged at $500 \mathrm{~g}$ for $10 \mathrm{~min}$ at $4{ }^{\circ} \mathrm{C}$ to remove cellular debris, and concentrated 10 -fold using Lenti- $\mathrm{X}$ concentrator (Takara Bio, Mountain View, CA, USA ). CasRx-GFP lentiviral particles were produced by co-transfecting plasmids encoding CasRx-GFP (PXR001; Addgene, Cambridge, MA, USA) with VSV-G envelope (pMD2.G; Addgene, Cambridge, MA, USA) and packaging (psPAX2; Addgene, Cambridge, MA, USA) into Lenti- $X^{\mathrm{TM}}$ cells. Culture supernatants were harvested $48 \mathrm{~h}$ post-transfection, clarified cell debris by centrifugation at $500 \times g$ for 10 min at $4{ }^{\circ} \mathrm{C}$, and concentrated 10 -fold using Lenti-X concentrator (Takara Bio, Mountain View, CA, USA). To obtain cells with stable CasRx-GFP expression, Lenti- ${ }^{\mathrm{TM}}$ cells were transduced by spinoculation at $800 \mathrm{~g}$ for $4 \mathrm{~h}$ with CasRx-GFP lentivirus in growth media containing $8 \mu \mathrm{g} / \mathrm{mL}$ polybrene. Forty-eight hours after transduction, the top $5 \%$ of cells expressing the highest levels of CasRx-GFP were sorted using BD FACS ARIA II (BD Bioscience, Franklin Lakes, NJ, USA). The CasRx-GFP expressing cells were expanded and screened for CasRx expression using qPCR (primers listed in Supplementary Table S1).

CasRx-gRNA transfection and measurement of HIV replication by flow cytometry Twenty-four hours before transfection, stable CasRx-GFP expressing Lenti- $X^{\mathrm{TM}}$ cells (LRx) were plated at $\sim 80,000$ cells per well in a 96 well flat bottom plate and incubated overnight to achieve $\sim 90 \%$ confluency before transfection. Two hundred nanograms (ng) of gRNA plasmids and $100 \mathrm{ng}$ of pBR43IeG-iRFP670-nef+ plasmids were co-transfected per well. Each gRNA was transfected in three wells. Forty-eight hours after transfection, the cells were detached and made into a single cell suspension using Versene. HIV replication was measured using a BD Accuri C6 Flow Cytometer (BD Bioscience, Franklin Lakes, NJ, USA) as percent HIV-iRFP670 expressing cells in HIV-guide RNA vs. the non-targeting control (NT) guide RNA transfected cells.

\subsection{Latency Model}

J1.1 cells were transfected with pVax-CasRx-GFP and gRNAs using Lonza $4 \mathrm{~d}$ nucleofector. Eight hours post-nucleofection, the cells were stimulated with phorbol 12-myristate 13 acetate (PMA) and ionomycin (Cell stimulation cocktail, eBioscience, ThermoFisher Scientific, Waltham, MA, USA), and cell supernatants were collected after $24 \mathrm{~h}$. 


\subsection{TZM-bl Reporter Assay}

HIV production in the cell supernatants was measured using TZM-bl reporter cell line. Supernatants were added to the TZM-bl reporter cells, and the cells were incubated for $48 \mathrm{~h}$. Cells were lysed, and luciferase activity was measured using Bright-Glo ${ }^{\mathrm{TM}}$ reagent (Promega, Madison, WI, USA) as previously described [31].

\section{Results}

\subsection{Design of gRNAs Targeting HIV-1}

We employed the siVirus online tool (http://siVirus.RNAi.jp/HIV/; accessed on 2 September 2021) [32] and the Los Alamos National Laboratory (LANL) database to select highly conserved sites in the HIV transcript. We selected twenty highly conserved target sites in the HIV-1 transcript. The chosen sites were in the regions encoding gag, pol, protease (prot), integrase (int), cPPT, and central termination sequence (CTS). We designed gRNAs to target the selected sites in HIV (HIV-gRNAs; Figure 1A; Supplementary Table S1). We also designed a non-targeting control gRNA (NT) that does not target HIV-1 or any sequence in the human transcriptome (Supplementary Table S2). Alignment and comparison of gRNA sequences showed $\geq 70 \%$ conservation in the HIV- 1 transcript sequences deposited in the LANL database (Supplementary Table S2).

To screen the HIV-targeting gRNAs, we developed an in vitro assay system comprising a stable cell line expressing RfxCas13d (CasRx-GFP) and a fluorescently labeled HIV-1 molecular clone. This allowed us to visualize the effect on HIV replication using flow cytometry. We used CasRx-GFP lentiviral construct encoding RfxCas13d fused to nuclear localization signal (NLS) at the N- and C-terminal and an enhanced green fluorescent protein (eGFP) [25]. A self-cleaving peptide sequence (2A) was inserted between Cas13d and eGFP coding sequences for simultaneous expression and cleavage of both proteins [25]. We transduced HEK-293 derived Lenti- ${ }^{\mathrm{TM}}$ cell line with the NLS-CasRx-GFP lentiviral particles and isolated cells expressing the highest NLS-CasRx-GFP using a fluorescenceactivated cell sorter (FACS; Supplementary Figure S1A). We confirmed CasRx expression in the sorted cells by quantitative PCR (qPCR; Supplementary Figure S1B). We refer to the Lenti- $X^{\mathrm{TM}}$ cell line with stable expression of NLS-CasRx-GFP as LRx here.

We designed a molecular clone of HIV-1 expressing a fluorescent tag to allow easy detection and quantification of virus infection, replication, spread, and inhibition by the CRISPR/CasRx system. We used dpBR43IeG-nef+ clone \# 11349 (NIH AIDS reagent program) $[33,34]$, a full-length, chimeric, and replication-competent subtype B CXCR4tropic vector (X4-tropic), derived from HIV-1 vector pNL4-3, designed to co-express eGFP and nef from a single bicistronic RNA. We replaced eGFP with a near-infrared fluorescent protein, iRFP670. We refer to this vector as HIV-iRFP (Supplementary Figure S2). HIV-iRFP vector can produce infectious HIV-1 particles that can infect T cells with CD4 and CXCR4 surface expression. The construct can also be used to generate pseudotyped lentiviral particles with the VSV-G envelope to infect a broader range of cell types.

We co-transfected the plasmids encoding NT or HIV-gRNAs, and HIV-iRFP vector in LRx cells, and $48 \mathrm{~h}$ (h) post-transfection, measured viral replication by flow cytometry as percent iRFP expressing cells and mean fluorescent intensity (MFI) of iRFP670 expression (Supplementary Figure S3). We also measured the production of infectious virions in the supernatant in HIV-gRNAs and NT transfected cells using a reporter cell line, TZM-bl. The TZM-bl cell line is a derivative of HeLa cells that express CD4, CCR5, and CXCR4 and contains an integrated reporter gene for firefly luciferase and $E$. coli $\beta$-galactosidase under the control of an HIV-1 long terminal repeat (LTR) [29], permitting sensitive and accurate measurements of infection. Individual gRNAs targeting pol/prot (BR02, BR18, BR21, BR23, BR24, BR25, BR26), and pol/int (BR16, BR30, BR33, BR34, BR43, BR04, BR29) genes showed $>70 \%$ reduction in HIV-1 replication as indicated by both the percent iRFP expressing cells (Figure 1B) as well as production of infectious HIV particles (Figure 1C) measured by TZM-bl reporter cell line compared to NT. 
A

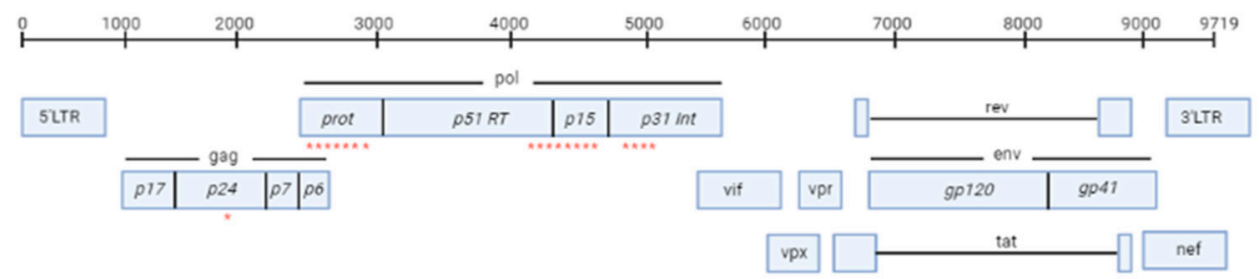

B

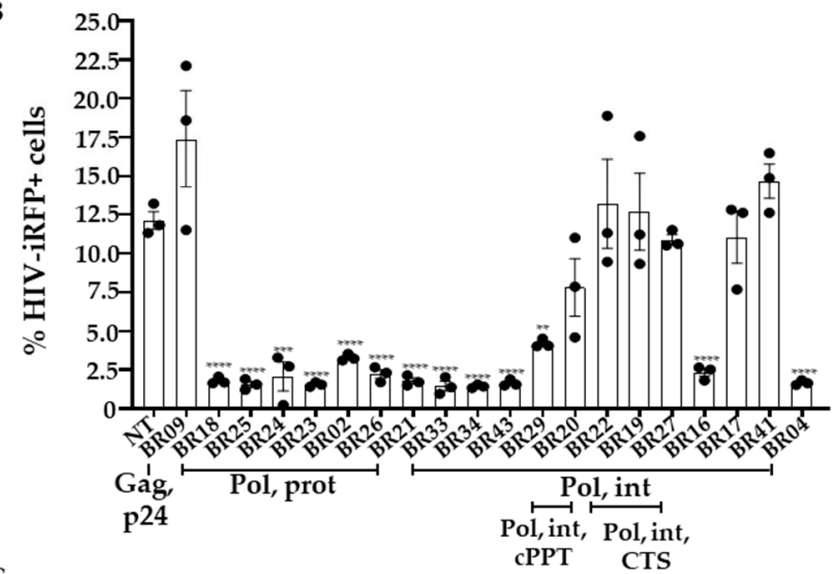

C

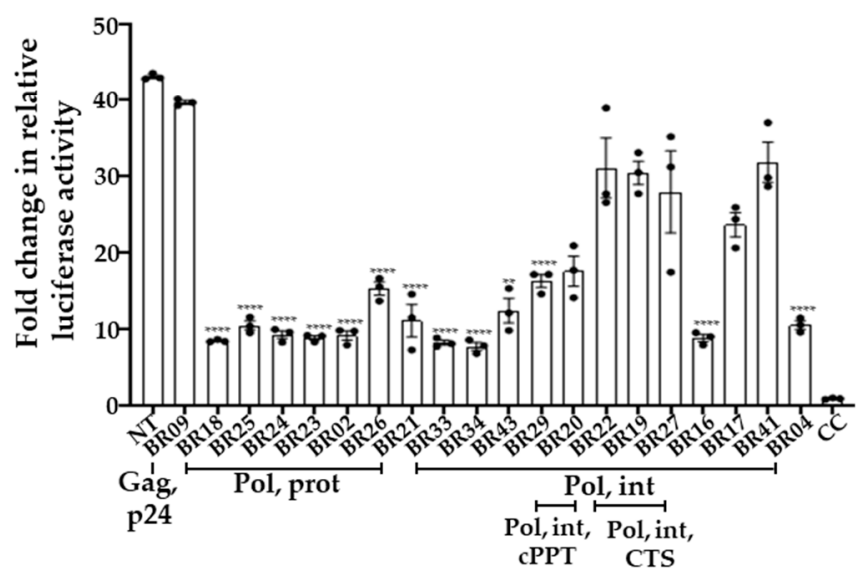

Figure 1. CRISPR/CasRx with HIV-specific single guide RNAs (gRNA) inhibits HIV-1 replication (A) schematic representation of HIV genome and gRNA binding sites (red stars; HIV sequence compendium 2018); (B) Lenti-XTM cells with stable CasRx-GFP expression (LRx) cells were cotransfected with plasmid encoding gRNA and HIV-encoding iRFP670 fluorescent marker (HIViRFP). Forty-eight hours after transfection, expression of CasRx-GFP and HIV-iRFP were measured by flow cytometry. Positions of gRNA sequences in HIV transcript are indicated on the X-axis; (C) Supernatants collected from the LRx cells transfected with HIV-iRFP and HIV-gRNA or NT plasmids were added to the reporter cell line TZM-bl containing luciferase gene under HIV-LTR. Relative luciferase expression was measured after $48 \mathrm{~h}$ and presented as a fold change in relative luciferase activity normalized to cells only control (CC). The means \pm s.e.m. are depicted as horizontal and vertical bars for each group, respectively. ANOVA tests with Bonferroni correction were used for statistical comparisons, and two-tailed $p$ values are indicated. ${ }^{* * *} p<0.0001$; $^{* * *} p<0.001,{ }^{* *} p<0.01$.

\subsection{Efficient Inhibition of HIV Using Simultaneous Targeting of Four Distant Sites}

Based on our preliminary analyses (Figure 1), we selected four gRNAs (BR04, BR23, BR34, BR29) targeting non-overlapping sites in the HIV-1 transcript for poly-gRNA assembly (polyHIV) and highly conserved sequences in the gRNA seed region (Supplementary Table S3). We transfected the LRx cells with plasmids encoding polyHIV or polyNT along with HIV-iRFP vector. The cells transfected with polyHIV showed $>90 \%$ reduction in HIV-1 replication, as indicated by both the percent iRFP expressing cells (Figure 2A), and 
production of infectious HIV particles (Figure 2B) compared to polyNT control. We constructed a single lentiviral vector expressing CasRx and four guide RNAs. The Lenti- $\mathrm{X}^{\mathrm{TM}}$ cell line was transduced with the CasRx-GFP-polyNT or CasRx-GFP-polyHIV lentiviral particles, and single cells expressing the highest GFP were isolated using FACS. The cells with stable expression of CasRx-polyNT (LRx-polyNT) or CasRx-polyHIV (LRx-polyHIV) were transfected with HIV-iRFP. The cells expressing CasRx-polyHIV showed a 99\% reduction in HIV replication, as indicated by both the percent iRFP expressing cells (Figure 2C) and the production of infectious HIV particles (Figure 2D). The above experiments were repeated using catalytically inactive CasRx (dCasRx) and observed no change in HIV-RFP expression in HIV-gRNAs vs. NT gRNA transfected cells (Supplementary Figure S4). These data further confirmed efficient targeting and inhibition of HIV replication by CasR $x$ and HIV-targeting gRNAs.

A

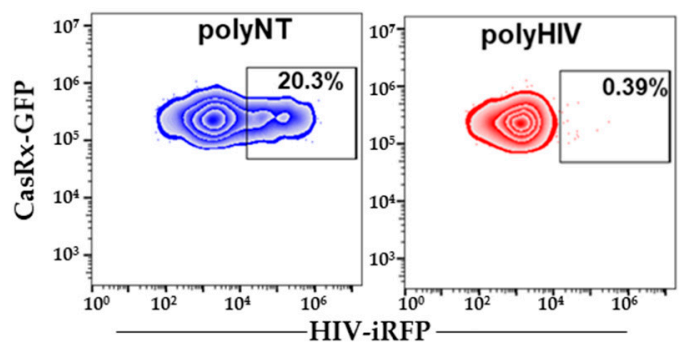

C

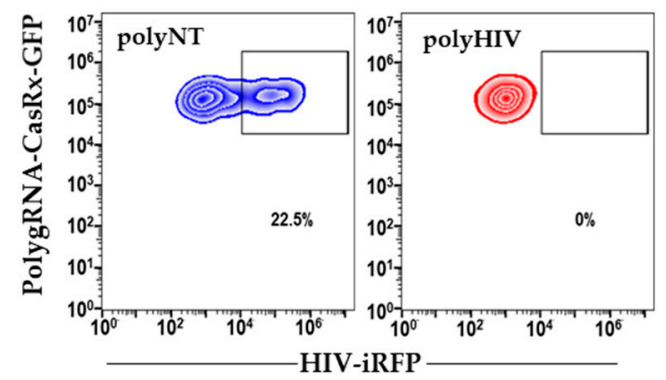

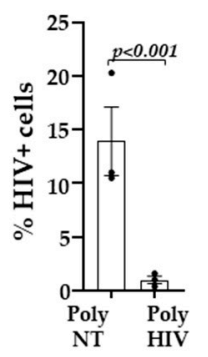

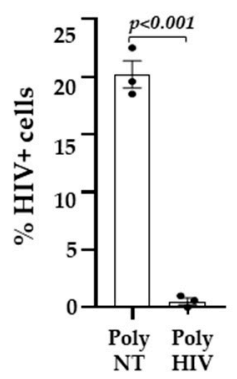

B

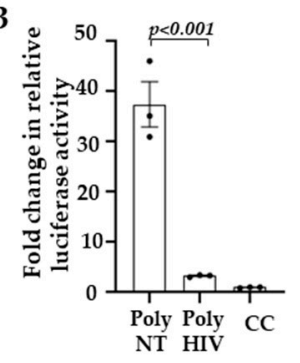

D

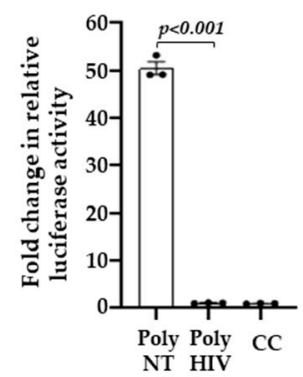

Figure 2. Inhibition of HIV-1 RNA by simultaneous targeting of distinct regions. (A) LRx cells were transfected with plasmid poly-gRNAs targeting HIV (polyHIV; red) or non-targeting control (polyNT) and HIV-iRFP. Forty-eight hours after transfection, expression of CasRx-GFP and HIV-iRFP were measured by flow cytometry; (B) supernatants collected from LRx cells transfected with HIV-iRFP and polyHIV or polyNT plasmids were added to the reporter cell line TZM-bl containing luciferase gene under HIV-LTR. Relative luciferase expression was measured after $48 \mathrm{~h}$ and presented as a fold change in relative luciferase activity normalized to cells only control (CC); (C) Lenti- $X^{\mathrm{TM}}$ cells with stable expression of CasRx-polyNT (blue) or CasRx-polyHIV (red) were transfected with HIV-iRFP. Forty-eight hours after transfection, expression of CasRx-GFP and HIV-iRFP were measured by flow cytometry; (D) supernatants collected from HIV-infected CasRx-polyHIV and CasRx-polyNT cells were added to the reporter cell line TZM-bl containing luciferase gene under HIV-LTR. Relative luciferase expression was measured after $48 \mathrm{~h}$ and presented as a fold change in relative luciferase activity normalized to cells only control (CC). The means \pm s.e.m. are depicted as horizontal and vertical bars for each group, respectively. The Student's t-test was used for statistical comparisons, and two-tailed $p$ values are indicated.

\subsection{Does Cytoplasmic CasRx Target Incoming HIV-1 RNA?}

To address if CasRx and gRNAs can target the incoming HIV-1 in the cytoplasm, we engineered the CasRx protein to accumulate in the cytoplasm. We replaced the nuclear localization signals (NLS) with the MAPK nuclear export signal (NES) such that CasRx-NES protein is localized to the cytoplasm. We transfected Lenti- $X^{\mathrm{TM}}$ cells with plasmids encoding CasRx-NES or CasRx-NLS and gRNAs. Twenty-four hours post-infection, the cells were infected with HIV-iRFP virus particles pseudotyped with Vesicular Stomatitis Virus G 
protein (VSV-G). Inhibition of virus infection in the polyHIV vs. polyNT transfected cells was assessed by flow cytometry $48 \mathrm{~h}$ post-infection. Cells transfected with nuclear (NLS) and cytoplasmic (NES) CasRx significantly reduced HIV replication in polyHIV gRNA transfected cells compared to polyNT transfected cells. However, the nuclear localization of CasRx was more effective in inhibiting HIV-1 replication than the cytoplasmic CasRx (Figure 3).
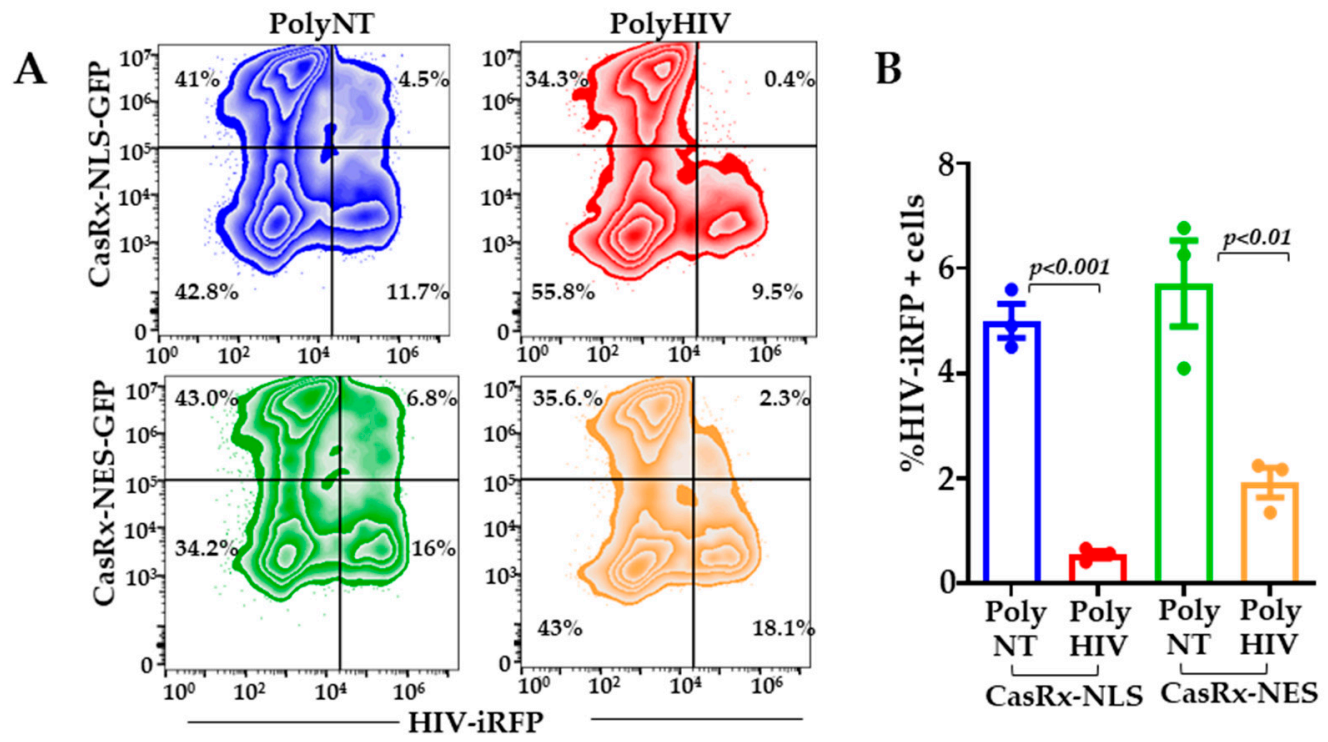

Figure 3. Nuclear localization of CasRx mediates optimal inhibition of HIV-1. Lenti- $\mathrm{X}^{\mathrm{TM}}$ cells were transfected with plasmid encoding CasRx-NLS-GFP, CasRx-NES-GFP, poly-gRNAs targeting HIV (polyHIV), or non-targeting control (polyNT). Twenty-four hours after transfections, the cells were infected with VSV-G pseudotyped HIV-iRFP. (A) Forty-eight hours after infection, expression of CasRx-GFP and HIV-iRFP were measured by flow cytometry; (B) \%iRFP expressing cells in polyHIV vs. polyNT gRNAs transfected cells were compared in all experimental groups. The means \pm s.e.m. are depicted as horizontal and vertical bars for each group, respectively. The Student's t-test was used for statistical comparisons, and two-tailed $p$ values are indicated.

\subsection{CasRx Inhibits HIV-1 Replication in Primary $\mathrm{CD}^{+} \mathrm{T}$ Cells}

To facilitate better nucleofection efficiency in the primary $\mathrm{CD}^{+} \mathrm{T}$ cells, we cloned CasRx in a mammalian expression vector, $\mathrm{pVax1}$ ( $\mathrm{pVax}-\mathrm{CasRx})$. We transfected activated $\mathrm{CD}^{+} \mathrm{T}$ cells with plasmids encoding pVax-CasRx and gRNAs (polyHIV or polyNT) using nucleofection. The cells were infected with the X4-tropic HIV-iRFP virus particles $18 \mathrm{~h}$ posttransfection. HIV-iRFP expression was measured by flow cytometry $48 \mathrm{~h}$ after infection. The cells expressing pVax-CasRx and polyHIV significantly reduced HIV-iRFP expression compared to pVax-CasRx and polyNT (Figure 4).

\subsection{CasRx Inhibits HIV-1 Expression from Latent Provirus}

We used the human T cell line, J1.1 latency model, to test whether CasRx and HIVgRNAs degrade HIV transcripts reactivated from HIV provirus. J1.1 is a chronically infected latent cell line cloned by limiting dilution from HIV-infected Jurkat cells and produces replication-competent HIV upon stimulation with latency reversal agents (LRA) [30]. We co-transfected J1.1 cells with plasmids encoding pVax-CasRx and gRNAs (polyHIV or polyNT) by nucleofection. The transfected cells were stimulated with PMA and ionomycin. We measured the production of infectious virions in the supernatant using a reporter cell line, TZM-bl (Figure 5A). Flow cytometry analyses showed that $>80 \%$ of the nucleofected J1.1 cells expressed pVAX-CasRx (Figure 5B). We observed a significant reduction in HIV production in the cells transfected with polyHIV compared to polyNT (Figure 5C). These 
data indicate that CasRx-gRNAs can be used to suppress reactivated HIV-1 from latently infected cells.

A

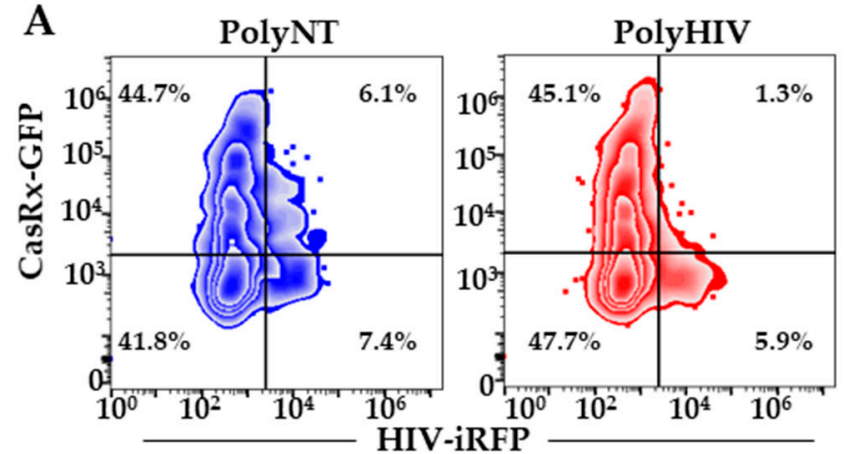

B

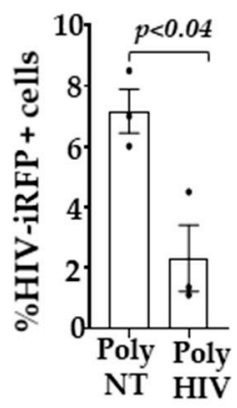

Figure 4. CasRx-silencing inhibited HIV-1 replication in $\mathrm{CD}^{+} \mathrm{T}$ cells. We transfected activated CD4 ${ }^{+}$ T cells with pVax1-CasRx-GFP, non-targeting (polyNT), or HIV-targeting (polyHIV) gRNA plasmids by nucleofection ( $\mathrm{n}=3$ distinct donors) and infected the cells with HIV-iRFP. (A) We measured HIV-iRFP expression $48 \mathrm{~h}$ post-infection by flow cytometry; (B) \%iRFP expressing cells in polyHIV vs. polyNT gRNAs transfected cells were compared. The means \pm s.e.m. are depicted as horizontal and vertical bars for each group, respectively. Each dot represents an individual donor. The paired $t$-test was used for statistical comparisons, and two-tailed $p$ values are indicated.

A.

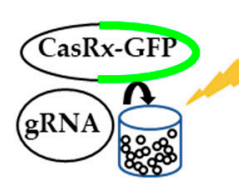

Nucleofection

B.

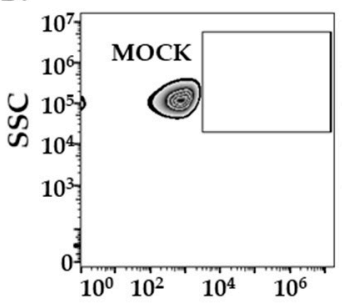

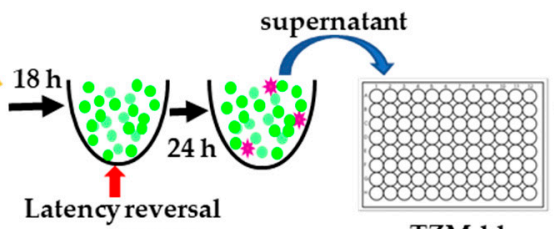

TZM-bl

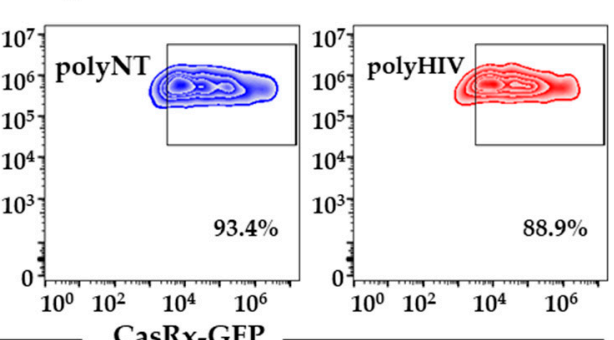

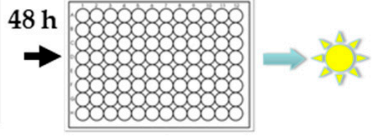

C.

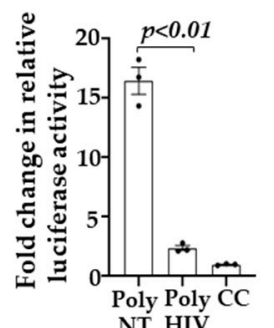

Figure 5. CasRx-silencing reduces HIV-1 expression from latent provirus (A) We nucleofected J1.1 cells with plasmids encoding gRNAs and CasRx-GFP and stimulated them with a latency reversal reagent (LRA; PMA), collected the supernatants $24 \mathrm{~h}$ post-stimulation and added these supernatants to the TZM-bl cells. Relative luciferase expression was measured after $48 \mathrm{~h}$ and presented as a fold change in relative luciferase activity normalized to the cells only control (CC); (B) GFP expression by $>80 \%$ of J1.1 cells indicated successful transfection with CasRx-GFP and gRNA plasmids; (C) Supernatants from cells transfected with gRNAs targeting HIV (polyHIV) vs. non-targeting (polyNT) showed significantly reduced luciferase activity. The means \pm s.e.m. are depicted as horizontal and vertical bars for each group, respectively. The Student's $t$-test was used for statistical comparisons, and two-tailed $p$ values are indicated.

\section{Discussion}

In this study, we present data demonstrating the CRISPR/CasRx nuclease system as an alternative treatment option against HIV. A major problem in developing effective countermeasures against HIV is viral diversity due to the error-prone nature of reverse transcriptase [35]. To overcome the diversity of HIV, several groups have developed vaccine candidates targeting the conserved regions [36-38]. This is because alterations in the conserved regions entail a fitness cost to the virus. We have used a novel RNA editing 
tool (CRISPR/CasRx) to target conserved regions of HIV and inhibit its replication in the current project. Out of the 20 gRNA screened, we identified 13 gRNAs highly effective in suppressing HIV replication. Recently, Wessels et al. [28] showed that the seed region (15-21 nucleotides) in gRNA is critical for CRISPR/Cas13d activity. A single mismatch in the seed region led to diminished activity, and two or three mismatches led to severe reduction in Cas13d activity in this study. We have estimated variation in the circulating HIV-1 sequences targeted by the four distant gRNAs used for simultaneous targeting in our study. Our analyses showed that the sequences targeted by these four gRNAs are very well conserved in the circulating HIV-1 sequences, with $\geq 95 \%$ conservation in the seed region of these gRNAs. The sequences targeted by two gRNAs, BR04 and BR29, showed no mismatches whereas sequences targeted by BR34 and BR41 showed a single mismatch in $<5 \%$ of the circulating HIV-1 sequence.

Wessels et al. also developed an algorithm to reliably predict predict functional efficacy of gRNAs based on specific sequence and structural features, and partition gRNAs into four quartiles based on the efficacy score. The gRNAs in the top two predicted efficacy quartiles (Q4 and Q3) showed high knockdown efficiency. Using their freely available algorithm [28], we calculated efficacy scores. As predicted by the scores, all 13 highly effective gRNAs were in the top two quartiles. Most of the effective gRNAs were in the pol gene. HIV pol and gag are the two most conserved regions of the group M HIV clades [35]. Mutations in HIV pol gene in patients often result in reduced viral replicative fitness and pathogenicity $[39,40]$. To make our HIV-targeting approach more stringent, we generated a guide RNA construct (polyHIV, including BR04, BR23, BR29, BR34) that simultaneously targeted four distinct sites in highly conserved regions. With simultaneous targeting of four distinct conserved regions in HIV-1 sequence, we showed $>90 \%$ inhibition of in vitro HIV replication. The gRNA target regions included the active site of the protease enzyme (BR23), the central polypurine tract (cPPT; BR29), the catalytic core domain of integrase (CCD, BR34), and the c-terminal domain (CTD; BR04) of integrase. Importantly, these target sites were conserved in most of the circulating HIV-1 strains and showed $>95 \%$ conservation in the seed region of gRNA, which is most critical for CasRx nuclease activity. Thus, we anticipate that this approach will be effective against all the HIV-1 clades.

The cellular location of CasRx nuclease is critical for efficient degradation of target RNA. It has been reported that cytoplasmic expression of CasRx is more effective against viruses that complete their life cycle in the cytoplasm. In our study, the nuclear localization of CasRx was found to be more effective against HIV than its cytoplasmic expression. Konerman et al. showed that nuclear localization signal increased CasRx activity in mammalian cells [25]. The ability to degrade RNA in the nucleus concurrently with transcription may confer CasRx superior gene knockdown efficiency. We believe this is advantageous over the siRNAs approach, as RNAi machinery is less effective in the nucleus.

The main target of HIV-1 infection is the $\mathrm{CD}^{+} \mathrm{T}$ cells [41]. We tested the efficacy of our antiviral cargo in primary $\mathrm{CD}^{+} \mathrm{T}$ cells as well as lymphocytic cell lines. CasRx and gRNA plasmid nucleofection inhibited HIV replication in primary $\mathrm{CD}^{+} \mathrm{T}$ cells and suppressed the expression of viral RNA from activated latent HIV-1 provirus. These results indicate that the CRISPR/CasRx system works in primary cells and can be effective in vivo. We are now developing methods to deliver our antiviral approach in animal models efficiently.

In vitro, RNAi against the virally transcribed RNA is highly effective in the short term at inhibiting HIV-1 replication [20,42-46]. There are several limitations to the use of si/shRNAs. RNA structural constraints may limit the accessibility of the target sequence to si/shRNAs. HIV-1 escapes siRNA-mediated silencing by two mechanisms. HIV-1 is a highly mutagenic virus owing to the lack of proofreading activity within reverse transcriptase, RNA hypermutations induced by APOBEC3G, and viral genetic recombination [10-12]. Thus sequence diversity of HIV limits the effective target sites to the highly conserved regions. Additionally, acquired mutations within or outside the target site alter its accessibility due to changes in sequence or RNA structure, resulting in the escape of mutant virus [19]. In addition, HIV-1 infection has been shown to suppress 
endogenous RNAi machinery [13-18]. Furthermore, shRNA/siRNA therapies have the potential for large-scale off-target cleavage caused by mismatched-siRNA, induction of innate immune response caused by double-stranded RNA, and overloading of the host miRNA pathway $[47,48]$. The expression and activity of CRISPR/Cas13d are independent of cellular RNAi or microRNA machinery. Thus, it will remain effective in the HIV-infected cells with suppressed cellular RNAi pathways.

Type VI CRISPR nucleases have recently been discovered as site-specific RNA-guided, RNA-targeting effectors [23-26,49]. The nuclease activity of these proteins allows gene knockdown without genomic alteration. Cas13 proteins are divided into various subtypes, including Cas13a, Cas13b, and Cas13d. Cas13a and Cas13b require a protospacer flanking sequence (PFS), whereas Cas13d is PFS independent [25,50,51]. CRISPR/RfxCas13d (CasRx) is the optimized version of Cas13d by Konerman et al. [25]. CasRx has superior knockdown efficiency compared to currently available methods, such as small hairpin RNA (shRNA) interference, dCas9-mediated transcriptional inhibition (CRISPRi), and Cas13a/Cas13b RNA knockdown [25]. Cas13a has been shown to reduce the viral RNA of Dengue virus 2 (DENV2) [52], HIV-1 [53], influenza A virus (FLUAV) [54], and SARSCoV2 [54]. Cas13b has been used to target Chikungunya virus in a mosquito cell line [55]. Cas13d has been shown to inhibit SARS-CoV-2 infection in vitro and vivo [56] and FLUAV in human lung epithelial cells [56]. However, the off-target effects remain a major concern with RNA targeting strategies. In vitro, Cas13 orthologs have been demonstrated to have limited off-target effects compared to RNAi $[23,25]$. CasRx was shown to have the least off-target effects compared to other Cas13 orthologs [24,25]. Recently Cas13a, used in most studies, showed collateral cleavage of untargeted cellular RNA in human glioma cells [57]. CasRx in mice and human neuronal cell lines showed efficient downregulation of the targeted gene while the transcriptional level of other genes, especially the typical neuronal genes, remained unchanged. This absence of collateral cleavage underlines CasRx as a promising Cas13 ortholog for in vivo knockdown therapies [58].

CRISPR/Cas9, a popular gene-editing tool, has been recently shown to treat HIV-1 effectively in vitro [59-68] and animal models when administered in combination with antiretroviral therapy $[69,70]$. This tool is being refined to cope with HIV-1 genetic diversity, off-target effects, harmful effects of large and dramatic genome rearrangements, generation of escape variants due to Cas9-induced mutants [63-66,71-73]. Combined CRISPR-Cas9 and RNAi mediated attack on distinct HIV-1 DNA and RNA sequences showed additive inhibition of viral replication, delay, and even prevention of virus escape [74]. Given the limitations of RNAi, combination trial therapy with CRISPR/CasRx and Cas9 simultaneously targeting multiple distinct sequences in HIV RNA and DNA will effectively reduce the initial viral burden and inhibit viral escape. CasRx with multiple gRNAs targeting conserved sites in HIV could also be used as a combinatorial regimen with latency reversal agents in 'shock and kill' approaches to reduce the viral burden and de novo infection by the reactivated virus.

CRISPR/Cas13d is encoded in the bacterial genome, and its optimized version (CasRx) can function in human cells to decay or edit cellular RNA without using endogenous components [25]. Cas13d/CasRx has an additional advantage of its small size that enables single vector Adeno-associated Virus (AAV) delivery of Cas13Rx and gRNA in vivo [25]. Recently, CasRx was functional when injected as RNA or ribonucleoprotein complexes with synthetic guide RNAs in zebrafish, medaka, killifish, mouse embryos, and drosophila [75]. AAV-mediated delivery of CasRx and gRNAs in mouse liver was successfully used to knock down target metabolic genes [76]. Further in vitro studies with different clinical strains of CCR5-tropic HIV-1 and in vivo studies in animal models are warranted to assess the efficacy of this promising CRISPR/CasRx antiviral approach for a durable and functional cure of HIV. 


\section{Conclusions}

CRISPR/CasRx nuclease system is a promising alternative tool against acute and chronic viral infections. We have demonstrated the effective use of this technology against HIV-1. Simultaneous delivery of a single vector with four gRNAs targeting nonoverlapping conserved regions of HIV-1 is a robust approach to inhibit HIV replication. This approach will impede the generation of escape variants which is a significant problem in the field. This RNA-targeting strategy is easily programmable to target any host factor or RNA virus. We anticipate that it will be highly efficient against any RNA virus, especially highly mutable and infectious viruses. Our promising in vitro results warrant further optimization of in vivo delivery and assessment of efficacy, immunogenicity, and safety of this promising therapeutic modality against HIV.

Supplementary Materials: The following are available online at https:/ /www.mdpi.com/article/ 10.3390/v13091850/s1, Figure S1: Gaiting strategy, Figure S2: Plasmid design for expression of HIV-1 encoding fluorescent tag, Figure S3: Measurement of viral replication by flow cytometry, Figure S4: Catalytically inactive CasRx (dCasRx) with HIV-specific guide RNAs do not affect HIV replication, Figure S5: Plasmid Design - pKLV2-U6-CasRx-(pre-gRNA)-PGKpuro2ABFP-W, Table S1: Oligonucleotide primers, Table S2: guide RNA design, Table S3: variation in gRNA seed sequence.

Author Contributions: Conceptualization, H.N., V.K., and S.K.; methodology, H.N., H.W., S.J., V.K., and S.K.; writing—original draft preparation, H.N.; writing—review and editing, H.N., H.W., S.J., V.K., and S.K.; supervision, S.K.; project administration, S.K.; funding acquisition, V.K., and S.K. All authors have read and agreed to the published version of the manuscript.

Funding: H.N., S.J., H.W., V.K., and S.K. are supported by the Texas Biomedical Research Institute, Texas Biomed Forum award (2019) to V.K. and San Antonio precision partnerships award to S.K. Research reported in this publication was supported in parts by the National Institute of Allergy and Infectious Diseases of the National Institutes of Health under Award Number R56AI150371 (S.K.), R21 AI140956 (S.K.). The content is solely the responsibility of the authors and does not necessarily represent the official views of the National Institutes of Health.

Institutional Review Board Statement: Not applicable. Peripheral blood lymphocytes were obtained from commercially available single-donor buffy coats from Innovative research https: / www. innov-research.com/ (accessed on 20 July 2021).

Informed Consent Statement: Not applicable.

Data Availability Statement: The data presented in this study are available in Figures 1-5, Supplementary Figures S1-S5, and supplementary Tables S1-S3.

Acknowledgments: We thank Vida Hodara and the Texas Biomed Biology core for cell sorting.

Conflicts of Interest: The authors declare no conflict of interest.

\section{References}

1. Liu, C.; Ostrow, D.; Detels, R.; Hu, Z.; Johnson, L.; Kingsley, L.; Jacobson, L.P. Impacts of HIV infection and HAART use on quality of life. Qual. Life Res. 2006, 15, 941-949. [CrossRef]

2. Chun, T.W.; Murray, D.; Justement, J.S.; Hallahan, C.W.; Moir, S.; Kovacs, C.; Fauci, A.S. Relationship Between Residual Plasma Viremia and the Size of HIV Proviral DNA Reservoirs in Infected Individuals Receiving Effective Antiretroviral Therapy. J. Infect. Dis. 2011, 204, 135-138. [CrossRef]

3. Parisi, S.G.; Andreis, S.; Mengoli, C.; Scaggiante, R.; Ferretto, R.; Manfrin, V.; Cruciani, M.; Giobbia, M.; Boldrin, C.; Basso, M.; et al Baseline Cellular HIV DNA Load Predicts HIV DNA Decline and Residual HIV Plasma Levels during Effective Antiretroviral Therapy. J. Clin. Microbiol. 2012, 50, 258-263. [CrossRef]

4. Pennings, P.S. HIV Drug Resistance: Problems and Perspectives. Infect. Dis. Rep. 2013, 5 (Suppl. 1), e5. [CrossRef] [PubMed]

5. Max, B.; Sherer, R. Management of the adverse effects of antiretroviral therapy and medication adherence. Clin. Infect. Dis. 2000, 30 (Suppl. 2), S96-S116. [CrossRef]

6. Chun, T.W.; Finzi, D.; Margolick, J.; Chadwick, K.; Schwartz, D.; Siliciano, R.F. In vivo fate of HIV-1-infected T cells: Quantitative analysis of the transition to stable latency. Nat. Med. 1995, 1, 1284-1290. [CrossRef]

7. Siliciano, J.D.; Siliciano, R.F. Recent developments in the effort to cure HIV infection: Going beyond N = 1. J. Clin. Investg. 2016, 126, 409-414. [CrossRef] 
8. Ganor, Y.; Real, F.; Sennepin, A.; Dutertre, C.A.; Prevedel, L.; Xu, L.; Tudor, D.; Charmeteau, B.; Couedel-Courteille, A.; Marion, S.; et al. HIV-1 reservoirs in urethral macrophages of patients under suppressive antiretroviral therapy. Nat. Microbiol. 2019, 4, 633-644. [CrossRef]

9. Wong, M.E.; Jaworowski, A.; Hearps, A.C. The HIV Reservoir in Monocytes and Macrophages. Front. Immunol. 2019, 10, 1435. [CrossRef]

10. Armitage, A.E.; Deforche, K.; Chang, C.H.; Wee, E.; Kramer, B.; Welch, J.J.; Gerstoft, J.; Fugger, L.; McMichael, A.; Rambaut, A.; et al. APOBEC3G-induced hypermutation of human immunodeficiency virus type-1 is typically a discrete "all or nothing" phenomenon. PLoS Genet. 2012, 8, e1002550. [CrossRef]

11. Burke, D.S. Recombination in HIV: An important viral evolutionary strategy. Emerg. Infect. Dis. 1997, 3, 253-259. [CrossRef] [PubMed]

12. Santoro, M.M.; Perno, C.F. HIV-1 Genetic Variability and Clinical Implications. ISRN Microbiol. 2013, 2013, 481314. [CrossRef] [PubMed]

13. Aqil, M.; Naqvi, A.R.; Bano, A.S.; Jameel, S. The HIV-1 Nef protein binds argonaute-2 and functions as a viral suppressor of RNA interference. PLoS ONE 2013, 8, e74472. [CrossRef]

14. Bennasser, Y.; Le, S.Y.; Benkirane, M.; Jeang, K.T. Evidence that HIV-1 encodes an siRNA and a suppressor of RNA silencing. Immunity 2005, 22, 607-619. [CrossRef]

15. Daniels, S.M.; Sinck, L.; Ward, N.J.; Melendez-Pena, C.E.; Scarborough, R.J.; Azar, I.; Rance, E.; Daher, A.; Pang, K.M.; Rossi, J.J.; et al. HIV-1 RRE RNA acts as an RNA silencing suppressor by competing with TRBP-bound siRNAs. RNA Biol. 2015, 12, 123-135. [CrossRef]

16. Gatignol, A.; Laine, S.; Clerzius, G. Dual role of TRBP in HIV replication and RNA interference: Viral diversion of a cellular pathway or evasion from antiviral immunity? Retrovirology 2005, 2, 65. [CrossRef]

17. Qian, S.; Zhong, X.; Yu, L.; Ding, B.; de Haan, P.; Boris-Lawrie, K. HIV-1 Tat RNA silencing suppressor activity is conserved across kingdoms and counteracts translational repression of HIV-1. Proc. Natl. Acad. Sci. USA 2009, 106, 605-610. [CrossRef]

18. Yeung, M.L.; Bennasser, Y.; Myers, T.G.; Jiang, G.; Benkirane, M.; Jeang, K.T. Changes in microRNA expression profiles in HIV-1-transfected human cells. Retrovirology 2005, 2, 81. [CrossRef]

19. Bobbin, M.L.; Burnett, J.C.; Rossi, J.J. RNA interference approaches for treatment of HIV-1 infection. Genome Med. 2015, 7, 50. [CrossRef]

20. Naito, Y.; Nohtomi, K.; Onogi, T.; Uenishi, R.; Ui-Tei, K.; Saigo, K.; Takebe, Y. Optimal design and validation of antiviral siRNA for targeting HIV-1. Retrovirology 2007, 4, 80. [CrossRef]

21. Leonard, J.N.; Schaffer, D.V. Computational design of antiviral RNA interference strategies that resist human immunodeficiency virus escape. J. Virol. 2005, 79, 1645-1654. [CrossRef]

22. Liu, C.; Liang, Z.; Kong, X. Efficacy Analysis of Combinatorial siRNAs against HIV Derived from One Double Hairpin RNA Precursor. Front. Microbiol. 2017, 8, 1651. [CrossRef] [PubMed]

23. Abudayyeh, O.O.; Gootenberg, J.S.; Essletzbichler, P.; Han, S.; Joung, J.; Belanto, J.J.; Verdine, V.; Cox, D.B.T.; Kellner, M.J.; Regev, A.; et al. RNA targeting with CRISPR-Cas13. Nature 2017, 550, 280-284. [CrossRef]

24. Cox, D.B.T.; Gootenberg, J.S.; Abudayyeh, O.O.; Franklin, B.; Kellner, M.J.; Joung, J.; Zhang, F. RNA editing with CRISPR-Cas13. Science 2017, 358, 1019-1027. [CrossRef]

25. Konermann, S.; Lotfy, P.; Brideau, N.J.; Oki, J.; Shokhirev, M.N.; Hsu, P.D. Transcriptome Engineering with RNA-Targeting Type VI-D CRISPR Effectors. Cell 2018, 173, 665-676.e14. [CrossRef]

26. Smargon, A.A.; Cox, D.B.T.; Pyzocha, N.K.; Zheng, K.; Slaymaker, I.M.; Gootenberg, J.S.; Abudayyeh, O.A.; Essletzbichler, P.; Shmakov, S.; Makarova, K.S.; et al. Cas13b Is a Type VI-B CRISPR-Associated RNA-Guided RNase Differentially Regulated by Accessory Proteins Csx27 and Csx28. Mol. Cell 2017, 65, 618-630 e7. [CrossRef]

27. Huang, F.; Spangler, J.R.; Huang, A.Y. In vivo cloning of up to $16 \mathrm{~kb}$ plasmids in E. coli is as simple as PCR. PLoS ONE 2017, 12, e0183974. [CrossRef]

28. Wessels, H.H.; Mendez-Mancilla, A.; Guo, X.; Legut, M.; Daniloski, Z.; Sanjana, N.E. Massively parallel Cas13 screens reveal principles for guide RNA design. Nat. Biotechnol. 2020, 38, 722-727. [CrossRef]

29. Sarzotti-Kelsoe, M.; Bailer, R.T.; Turk, E.; Lin, C.L.; Bilska, M.; Greene, K.M.; Gao, H.; Todd, C.A.; Ozaki, D.A.; Seaman, M.S.; et al. Optimization and validation of the TZM-bl assay for standardized assessments of neutralizing antibodies against HIV-1. J. Immunol. Methods 2014, 409, 131-146. [CrossRef]

30. Perez, V.L.; Rowe, T.; Justement, J.S.; Butera, S.T.; June, C.H.; Folks, T.M. An HIV-1-infected T cell clone defective in IL-2 production and $\mathrm{Ca}^{2+}$ mobilization after CD3 stimulation. J. Immunol. 1991, 147, 3145-3148.

31. Montefiori, D.C. Measuring HIV neutralization in a luciferase reporter gene assay. Methods Mol. Biol. 2009, 485, 395-405. [PubMed]

32. Naito, Y.; Ui-Tei, K.; Nishikawa, T.; Takebe, Y.; Saigo, K. siVirus: Web-based antiviral siRNA design software for highly divergent viral sequences. Nucleic Acids Res. 2006, 34, W448-W450. [CrossRef]

33. Schindler, M.; Munch, J.; Kirchhoff, F. Human immunodeficiency virus type 1 inhibits DNA damage-triggered apoptosis by a Nef-independent mechanism. J. Virol. 2005, 79, 5489-5498. [CrossRef] [PubMed] 
34. Schindler, M.; Wurfl, S.; Benaroch, P.; Greenough, T.C.; Daniels, R.; Easterbrook, P.; Brenner, M.; Munch, J.; Kirchhoff, F. Downmodulation of mature major histocompatibility complex class II and up-regulation of invariant chain cell surface expression are well-conserved functions of human and simian immunodeficiency virus nef alleles. J. Virol. 2003, 77, 10548-10556. [CrossRef]

35. Rolland, M.; Nickle, D.C.; Mullins, J.I. HIV-1 group M conserved elements vaccine. PLoS Pathog. 2007, 3, e157. [CrossRef]

36. Borthwick, N.; Ahmed, T.; Ondondo, B.; Hayes, P.; Rose, A.; Ebrahimsa, U.; Hayton, E.J.; Black, A.; Bridgeman, A.; Rosario, M.; et al. Vaccine-elicited human T cells recognizing conserved protein regions inhibit HIV-1. Mol. Ther. 2014, 22, 464-475. [CrossRef]

37. Kulkarni, V.; Valentin, A.; Rosati, M.; Alicea, C.; Singh, A.K.; Jalah, R.; Broderick, K.E.; Sardesai, N.Y.; Le Gall, S.; Mothe, B.; et al. Altered response hierarchy and increased T-cell breadth upon HIV-1 conserved element DNA vaccination in macaques. PLoS ONE 2014, 9, e86254. [CrossRef]

38. Nickle, D.C.; Rolland, M.; Jensen, M.A.; Pond, S.L.; Deng, W.; Seligman, M.; Heckerman, D.; Mullins, J.I.; Jojic, N. Coping with viral diversity in HIV vaccine design. PLoS Comput. Biol. 2007, 3, e75. [CrossRef]

39. Prado, J.G.; Parkin, N.T.; Clotet, B.; Ruiz, L.; Martinez-Picado, J. HIV type 1 fitness evolution in antiretroviral-experienced patients with sustained CD4+ T cell counts but persistent virologic failure. Clin. Infect. Dis. 2005, 41, 729-737. [CrossRef]

40. Deeks, S.G.; Barbour, J.D.; Martin, J.N.; Swanson, M.S.; Grant, R.M. Sustained CD4+ T cell response after virologic failure of protease inhibitor-based regimens in patients with human immunodeficiency virus infection. J. Infect. Dis. 2000, 181, 946-953. [CrossRef]

41. Cohn, L.B.; da Silva, I.T.; Valieris, R.; Huang, A.S.; Lorenzi, J.C.C.; Cohen, Y.Z.; Pai, J.A.; Butler, A.L.; Caskey, M.; Jankovic, M.; et al. Clonal CD4(+) T cells in the HIV-1 latent reservoir display a distinct gene profile upon reactivation. Nat. Med. 2018, 24, 604-609. [CrossRef]

42. Boden, D.; Pusch, O.; Silbermann, R.; Lee, F.; Tucker, L.; Ramratnam, B. Enhanced gene silencing of HIV-1 specific siRNA using microRNA designed hairpins. Nucleic Acids Res. 2004, 32, 1154-1158. [CrossRef]

43. Kim, D.H.; Rossi, J.J. Strategies for silencing human disease using RNA interference. Nat. Rev. Genet. 2007, 8, 173-184. [CrossRef]

44. Kretova, O.V.; Fedoseeva, D.M.; Gorbacheva, M.A.; Gashnikova, N.M.; Gashnikova, M.P.; Melnikova, N.V.; Chechetkin, V.R.; Kravatsky, Y.V.; Tchurikov, N.A. Six Highly Conserved Targets of RNAi Revealed in HIV-1-Infected Patients from Russia Are Also Present in Many HIV-1 Strains Worldwide. Mol. Ther. Nucleic Acids 2017, 8, 330-344. [CrossRef] [PubMed]

45. Ter Brake, O.; Konstantinova, P.; Ceylan, M.; Berkhout, B. Silencing of HIV-1 with RNA interference: A multiple shRNA approach. Mol. Ther. 2006, 14, 883-892. [CrossRef] [PubMed]

46. Yamagishi, M.; Ishida, T.; Miyake, A.; Cooper, D.A.; Kelleher, A.D.; Suzuki, K.; Watanabe, T. Retroviral delivery of promotertargeted shRNA induces long-term silencing of HIV-1 transcription. Microbes Infect. 2009, 11, 500-508. [CrossRef]

47. Jackson, A.L.; Burchard, J.; Schelter, J.; Chau, B.N.; Cleary, M.; Lim, L.; Linsley, P.S. Widespread siRNA “off-target” transcript silencing mediated by seed region sequence complementarity. RNA 2006, 12, 1179-1187. [CrossRef]

48. Jackson, A.L.; Linsley, P.S. Recognizing and avoiding siRNA off-target effects for target identification and therapeutic application. Nat. Rev. Drug Discov. 2010, 9, 57-67. [CrossRef]

49. Gootenberg, J.S.; Abudayyeh, O.O.; Lee, J.W.; Essletzbichler, P.; Dy, A.J.; Joung, J.; Verdine, V.; Donghia, N.; Daringer, N.M.; Freije, C.A.; et al. Nucleic acid detection with CRISPR-Cas13a/C2c2. Science 2017, 356, 438-442. [CrossRef] [PubMed]

50. Yan, W.X.; Chong, S.; Zhang, H.; Makarova, K.S.; Koonin, E.V.; Cheng, D.R.; Scott, D.A. Cas13d Is a Compact RNA-Targeting Type VI CRISPR Effector Positively Modulated by a WYL-Domain-Containing Accessory Protein. Mol. Cell 2018, 70, 327-339 e5. [CrossRef] [PubMed]

51. Zhang, C.; Konermann, S.; Brideau, N.J.; Lotfy, P.; Wu, X.; Novick, S.J.; Strutzenberg, T.; Griffin, P.R.; Hsu, P.D.; Lyumkis, D. Structural Basis for the RNA-Guided Ribonuclease Activity of CRISPR-Cas13d. Cell 2018, 175, 212-223 e17. [CrossRef]

52. Li, H.; Wang, S.; Dong, X.; Li, Q.; Li, M.; Li, J.; Guo, Y.; Jin, X.; Zhou, Y.; Song, H.; et al. CRISPR-Cas13a Cleavage of Dengue Virus NS3 Gene Efficiently Inhibits Viral Replication. Mol. Ther. Nucleic Acids 2020, 19, 1460-1469. [CrossRef] [PubMed]

53. Yin, L.; Zhao, F.; Sun, H.; Wang, Z.; Huang, Y.; Zhu, W.; Xu, F.; Mei, S.; Liu, X.; Zhang, D.; et al. CRISPR-Cas13a Inhibits HIV-1 Infection. Mol. Ther. Nucleic Acids 2020, 21, 147-155. [CrossRef]

54. Blanchard, E.L.; Vanover, D.; Bawage, S.S.; Tiwari, P.M.; Rotolo, L.; Beyersdorf, J.; Peck, H.E.; Bruno, N.C.; Hincapie, R.; Michel, F.; et al. Treatment of influenza and SARS-CoV-2 infections via mRNA-encoded Cas13a in rodents. Nat. Biotechnol. 2021, 39, 717-726. [CrossRef] [PubMed]

55. Tng, P.Y.L.; Carabajal Paladino, L.; Verkuijl, S.A.N.; Purcell, J.; Merits, A.; Leftwich, P.T.; Fragkoudis, R.; Noad, R.; Alphey, L. Cas13b-dependent and Cas13b-independent RNA knockdown of viral sequences in mosquito cells following guide RNA expression. Commun. Biol. 2020, 3, 413. [CrossRef]

56. Abbott, T.R.; Dhamdhere, G.; Liu, Y.; Lin, X.; Goudy, L.; Zeng, L.; Chemparathy, A.; Chmura, S.; Heaton, N.S.; Debs, R.; et al. Development of CRISPR as an Antiviral Strategy to Combat SARS-CoV-2 and Influenza. Cell 2020, 181, 865-876.e12. [CrossRef]

57. Wang, Q.; Liu, X.; Zhou, J.; Yang, C.; Wang, G.; Tan, Y.; Wu, Y.; Zhang, S.; Yi, K.; Kang, C. The CRISPR-Cas13a Gene-Editing System Induces Collateral Cleavage of RNA in Glioma Cells. Adv. Sci. (Weinh) 2019, 6, 1901299. [CrossRef]

58. Zhou, H.; Su, J.; Hu, X.; Zhou, C.; Li, H.; Chen, Z.; Xiao, Q.; Wang, B.; Wu, W.; Sun, Y.; et al. Glia-to-Neuron Conversion by CRISPR-CasRx Alleviates Symptoms of Neurological Disease in Mice. Cell 2020, 181, 590-603.e16. [CrossRef]

59. Ebina, H.; Misawa, N.; Kanemura, Y.; Koyanagi, Y. Harnessing the CRISPR/Cas9 system to disrupt latent HIV-1 provirus. Sci. Rep. 2013, 3, 2510. [CrossRef] 
60. Hu, W.; Kaminski, R.; Yang, F.; Zhang, Y.; Cosentino, L.; Li, F.; Luo, B.; Alvarez-Carbonell, D.; Garcia-Mesa, Y.; Karn, J.; et al. RNA-directed gene editing specifically eradicates latent and prevents new HIV-1 infection. Proc. Natl. Acad. Sci. USA 2014, 111, 11461-11466. [CrossRef]

61. Kaminski, R.; Chen, Y.; Fischer, T.; Tedaldi, E.; Napoli, A.; Zhang, Y.; Karn, J.; Hu, W.; Khalili, K. Elimination of HIV-1 Genomes from Human T-lymphoid Cells by CRISPR/Cas9 Gene Editing. Sci. Rep. 2016, 6, 22555. [CrossRef]

62. Liao, H.K.; Gu, Y.; Diaz, A.; Marlett, J.; Takahashi, Y.; Li, M.; Suzuki, K.; Xu, R.; Hishida, T.; Chang, C.J.; et al. Use of the CRISPR/Cas9 system as an intracellular defense against HIV-1 infection in human cells. Nat. Commun. 2015, 6, 6413. [CrossRef]

63. Wang, G.; Zhao, N.; Berkhout, B.; Das, A.T. CRISPR-Cas9 Can Inhibit HIV-1 Replication but NHEJ Repair Facilitates Virus Escape. Mol. Ther. 2016, 24, 522-526. [CrossRef] [PubMed]

64. Wang, G.; Zhao, N.; Berkhout, B.; Das, A.T. A Combinatorial CRISPR-Cas9 Attack on HIV-1 DNA Extinguishes All Infectious Provirus in Infected T Cell Cultures. Cell Rep. 2016, 17, 2819-2826. [CrossRef] [PubMed]

65. Wang, Z.; Pan, Q.; Gendron, P.; Zhu, W.; Guo, F.; Cen, S.; Wainberg, M.A.; Liang, C. CRISPR/Cas9-Derived Mutations Both Inhibit HIV-1 Replication and Accelerate Viral Escape. Cell Rep. 2016, 15, 481-489. [CrossRef] [PubMed]

66. Yin, C.; Zhang, T.; Li, F.; Yang, F.; Putatunda, R.; Young, W.B.; Khalili, K.; Hu, W.; Zhang, Y. Functional screening of guide RNAs targeting the regulatory and structural HIV-1 viral genome for a cure of AIDS. AIDS 2016, 30, 1163-1174. [CrossRef] [PubMed]

67. Yin, C.; Zhang, T.; Qu, X.; Zhang, Y.; Putatunda, R.; Xiao, X.; Li, F.; Xiao, W.; Zhao, H.; Dai, S.; et al. In Vivo Excision of HIV-1 Provirus by saCas9 and Multiplex Single-Guide RNAs in Animal Models. Mol. Ther. 2017, 25, 1168-1186. [CrossRef] [PubMed]

68. Zhu, W.; Lei, R.; Le Duff, Y.; Li, J.; Guo, F.; Wainberg, M.A.; Liang, C. The CRISPR/Cas9 system inactivates latent HIV-1 proviral DNA. Retrovirology 2015, 12, 22. [CrossRef] [PubMed]

69. Dash, P.K.; Kaminski, R.; Bella, R.; Su, H.; Mathews, S.; Ahooyi, T.M.; Chen, C.; Mancuso, P.; Sariyer, R.; Ferrante, P.; et al. Sequential LASER ART and CRISPR Treatments Eliminate HIV-1 in a Subset of Infected Humanized Mice. Nat. Commun. 2019, 10, 2753. [CrossRef]

70. Mancuso, P.; Chen, C.; Kaminski, R.; Gordon, J.; Liao, S.; Robinson, J.A.; Smith, M.D.; Liu, H.; Sariyer, I.K.; Sariyer, R.; et al. CRISPR based editing of SIV proviral DNA in ART treated non-human primates. Nat. Commun. 2020, 11, 6065. [CrossRef]

71. Lebbink, R.J.; de Jong, D.C.; Wolters, F.; Kruse, E.M.; van Ham, P.M.; Wiertz, E.J.; Nijhuis, M. A combinational CRISPR/Cas9 gene-editing approach can halt HIV replication and prevent viral escape. Sci. Rep. 2017, 7, 41968. [CrossRef] [PubMed]

72. Liang, C.; Wainberg, M.A.; Das, A.T.; Berkhout, B. CRISPR/Cas9: A double-edged sword when used to combat HIV infection. Retrovirology 2016, 13, 37. [CrossRef] [PubMed]

73. Yoder, K.E.; Bundschuh, R. Host Double Strand Break Repair Generates HIV-1 Strains Resistant to CRISPR/Cas9. Sci. Rep. 2016, 6, 29530. [CrossRef] [PubMed]

74. Zhao, N.; Wang, G.; Das, A.T.; Berkhout, B. Combinatorial CRISPR-Cas9 and RNA Interference Attack on HIV-1 DNA and RNA Can Lead to Cross-Resistance. Antimicrob. Agents Chemother. 2017, 61, e01486-17. [CrossRef]

75. Kushawah, G.; Hernandez-Huertas, L.; Abugattas-Nunez Del Prado, J.; Martinez-Morales, J.R.; DeVore, M.L.; Hassan, H.; Moreno-Sanchez, I.; Tomas-Gallardo, L.; Diaz-Moscoso, A.; Monges, D.E.; et al. CRISPR-Cas13d Induces Efficient mRNA Knockdown in Animal Embryos. Dev. Cell 2020, 54, 805-817.e7. [CrossRef] [PubMed]

76. He, B.; Peng, W.; Huang, J.; Zhang, H.; Zhou, Y.; Yang, X.; Liu, J.; Li, Z.; Xu, C.; Xue, M.; et al. Modulation of metabolic functions through Cas13d-mediated gene knockdown in liver. Protein Cell 2020, 11, 518-524. [CrossRef] 